\title{
Definitive diagnosis of neuroendocrine tumors using fine-needle aspiration-puncture guided by endoscopic ultrasonography
}

\author{
Joan Gornals ${ }^{1,2,3}$, Modesto $\operatorname{Varas}^{3}$, Isabel Catalá ${ }^{1}$, Sandra Maisterra ${ }^{1}$, Carlos Pons ${ }^{1}$, Domingo Bargalló , \\ Teresa Serrano ${ }^{1}$ and Joan Fabregat ${ }^{1}$
}

${ }^{\prime}$ Department of Enchoendoscopy. Service of Digestive Diseases, Pathology, and Digestive and General Surgery. Hospital Universitario de Bellvitge. Hospitalet de Llobregat, Barcelona. Spain. ${ }^{2}$ Department of Echoendoscopy. Centro Médico Delfos. Barcelona, Spain. ${ }^{3}$ Centro Médico Teknon. Barcelona, Spain

\begin{abstract}
Background: the detection and diagnosis of neuroendocrine tumors (NETs) is challenging. Endoscopic ultrasonography (EUS) has a significant role in the detection of NETs suspected from clinical manifestations or imaging techniques, as well as in their precise localization and cytological confirmation using EUS-Fineneedle aspiration-puncture (FNA).

Objective: to assess the usefulness and precision of EUS-FNA in the differential diagnosis and confirmation of NETs, in a retrospective review of our experience.

Patients and methods: in a total of 55 patients with suspected NETs who underwent radial or sectorial EUS, 42 tumors were detected in 40 cases. EUS-FNA using a $22 \mathrm{G}$ needle was performed for 16 cases with suspected functional (hormonal disorders: 6 cases) and non-functional NETs (10 cases). Ki 67 or immunocytochemistry (ICC) testing was performed for all.

There was confirmation in 9 cases ( 5 female and 4 male) with a mean age of 51 years (range: $41-81$ years).

All tumors were located in the pancreas except for one in the mediastinum and one in the rectum, with a mean size of $19 \mathrm{~mm}$ (range: $10-40 \mathrm{~mm}$ ).

Results: there were no complications attributable to FNA. Sensitivity was $100 \%$ and both precision and PPV were $89 \%$, as a false positive result suggested a diagnosis with NET during cytology that surgery finally revealed to be a pancreatic pseudopapillary solid tumor.

Conclusions: EUS-FNA with a $22 \mathrm{G}$ needle for NETs has high sensitivity and PPV at cytological confirmation with few complications.

Key words: Fine-needle aspiration-puncture (FNA) guided by endoscopic ultrasonography (EUS) or echoendoscopy. Neuroendocrine tumors (NETs). Pancreatic endocrine tumors (PETs). Immunocytochemistry. Immunohistochemistry. Chromogranin. Synaptophysin. Cytokeratin 19. Vimentin. Ki 67. CD56.
\end{abstract}

Received: $19-07-10$.

Accepted: 30-09-10.

Correspondence: M. Varas Lorenzo. C. M. Teknon. C/ Marquesa de Vilallonga 12. 08017 Barcelona, Spain.

e-mail: varas@dr.teknon.es
Gornals Joan, Varas Modesto, Catalá Isabel, Maisterra Sandra, Pons Carlos, Bargalló Domingo, Serrano Teresa, Fabregat Joan. Definitive diagnosis of neuroendocrine tumors using fine-needle aspiration-puncture guided by endoscopic ultrasonography. Rev Esp Enferm Dig 2011; 103: 123-128.

\section{INTRODUCTION}

The preoperative diagnosis and precise localization of neuroendocrine tumors (NETs), particularly pancreatic NETs (PNETs), is challenging, and vital for a definitive cure of patients (1). For non-functioning cases, confirmation by histology is most necessary because of potential differential diagnoses. PNETs share histological properties with carcinoids: both are considered to derive from the diffuse endocrine cell system; they unusually exhibit mitotic features (assessable using the Ki-67 index); they usually show electrodense granules that contain hormones and various peptides, chromogranins (A, B, C), neuron-specific enolase (NSE), and synaptophysin $(2,3)$.

PNETs are clinically classified as functional (ZollingerEllison syndrome, etc.) and non-functional. The clinical diagnosis of functional PNETs is relatively straightforward.

Most are benign (no metastases) and small, and may be associated with multiple endocrine neoplasia (MEN). Non-functional tumors are most common among PNETs, and have a high incidence of metastatic disease.

Their precise localization in the pancreas is difficult. Echoendoscopy or endoscopic ultrasonography (EUS) is a rather recently introduced diagnostic technique, and may diagnose tumors smaller than $1 \mathrm{~cm}$ (up to $3 \mathrm{~mm}$ ) in the pancreas head and body with a sensitivity above $85 \%$ (93\% in the larger series), whereas those in the tail are harder to assess (1). 
EUS allows fine-needle aspiration-puncture (FNA) under ultrasound (US) guidance (4), and the collection of material for cytology and histology with a yield nearing $90 \%$. In addition, immunocytochemistry (ICC) and immunohistochemistry (IHC) tests may be performed on obtained samples for chromogranin (C-A), synaptophysin, cytokeratin 19, and various hormones or peptides, with diagnoses that may reach $100 \%$ for cystic PNETs (5).

A recent classification proposed by WHO (2) assigned three categories to NETs: well-differentiated tumor, welldifferentiated carcinoma, and poorly differentiated carcinoma based on histology, size (limit: $2 \mathrm{~cm}$ ), and proliferation index $(\mathrm{Ki}-67=2 \%)$.

A TNM (tumor, node, and metastasis) classification has also been suggested for PNETs based on the WHO classification (3).

\section{OBJECTIVE}

To assess the usefulness and precision of EUS-FNA in the differential and confirmatory diagnosis of NETs using a retrospective review of our team's experience.

\section{PATIENTS AND METHOD}

For a total of 55 patients with suspected PNETs who underwent radial or sectorial EUS, 42 tumors were identified in 40 patients. Inclusion criteria for EUS-FNA: patients with presumed NET diagnosis with EUS, uncertain or non-functional.

For 16 cases $(8$ women and 8 men with a mean age of 56 , range: $41-92$ years with suspected functional (6 cases) and non-functional (10 cases) tumors, none of them cystic, EUS-FNA was performed using a $22 \mathrm{G}$ needle (Echotip Ultra, Cook Medical) with conventional technique. All cases underwent Ki67 testing or immunocytochemistry for chromogranin, synaptophysin, and various hormones or peptides.

There was surgical confirmation (the gold standard) in 9 patients; in the remaining cases imaging techniques and 12-month follow-up (the gold standard) were used to reach a definitive diagnosis.

From all 16 patients 9 ( 5 women, 4 men) were selected with a mean age of 51 years (range: 41-81 years).

All tumors were in the pancreas, and one was in the mediastinum and one in the rectum, with a mean size of $19 \mathrm{~mm}$ (range: 10 to $40 \mathrm{~mm}$ ) (Table I).

Regarding pancreatic tumors, three were in the head, two in the tail, and two in the body. Only two patients had metastases.

All examinations (EUS-FNA) were performed after collecting an informed consent, with prior coagulation testing, and using sedation (propofol) by an anesthetist.

A cytologist was in all cases present in the examination room where EUS-FNA procedures were carried out.
Diagnostic precision $(\mathrm{P})$, sensitivity $(\mathrm{S})$, specificity $(\mathrm{Sp})$, positive predictive value (PPV) and negative predictive value (NPV) were all analyzed using standard formulas.

\section{RESULTS}

There were no EUS-FNA-related complications (hemorrhage and perforation).

In the total series (16 cases) S was $100 \%$ with a $\mathrm{Sp}$ of 67\%, P and PPV of 93 and 92\%, respectively.

In patients with surgical confirmation (9 cases) sensitivity (S) was $100 \%$, and precision (P) and PPV were $89 \%$, as cytology yielded a false positive result that was eventually diagnosed as a solid pancreatic pseudopapillary tumor following surgical excision and tail pancreatectomy plus IHC.

\section{DISCUSSION}

EUS-FNA has been performed for PNETs for slightly over 10 years now. In earlier works both sensitivity and precision were low, with a specificity of $100 \%$ (6); however, they gradually increased, and sensitivity reached about $90 \%$ (94\% in the most extensive series in the literature) (6-22) (Table II).

Our findings are consistent with those in the literature (S: $100 \%)$.

Typical EUS findings include homogeneous pancreatic nodules or lesions that are hypoechogenic, solid, hypervascular, and encapsulated with well-delimited borders $(1,22,29)$, even non-functional ones (most of them) (22). NFPETs show the greatest sizes and are more advanced (Fig. 1).

The use of ICC techniques (chromogranin, synaptophysin, etc.) (cytokeratin 19) (23) considerably improves sensitivity on cytology material (Fig. 2).

The Ki 67 index (24-26) and microsatellite instability have also been assessed in samples $(27,28)$ to establish the benign or malignant nature of tumors, and hence their prognosis.

Algorithms are similar for PNETs and pancreatic cancers (PCs) $(4,29)$ (Fig. 3).

When a tumor is resectable according to computed tomography plus EUS, and both clinical and morphological features are consistent, laparoscopic or open surgery may be readily performed. For uncertain or non-functioning tumors EUS-FNA may be used to confirm diagnostic suspicion.

Sometimes a histological differential diagnosis is difficult between pancreatic endocrine tumors, solid pseudopapillary tumor, acinar cell carcinomas, mucinous tumors, and lymphoma/plasmocytoma. In recent years various cases of solid pseudopapillary tumor have been described where ICC reached the right diagnosis on EUS- 
Table I. Case report

\begin{tabular}{|c|c|c|c|c|c|}
\hline$N .^{\circ}$ & Age/Sex & Diagnosis & Size & FNA & $I C C / I H C$ \\
\hline$\overline{1}$ & $41 / \mathrm{M}$ & Insulinoma, nody-tail: & $12-15 \mathrm{~mm}$ & FNA + & $V+I C C$ \\
\hline 2 & 49/M & NF, head & $23 \times 25$ & FNA + & $V+I C C$ \\
\hline 3 & $42 / F$ & PET, tail (pseudopapillary) & $12 \times 14$ & FNA + & $\mathrm{F}+\mathrm{ICC}$ e IHC \\
\hline 4 & $46 / \mathrm{M}$ & PET, tail (Ki 67:10\%) & $13 \times 14$ & FNA + & $V+I C C$ \\
\hline 5 & $45 / \mathrm{M}$ & I-G, head & $40 \mathrm{~mm} . \mathrm{B}$ & FNA + & $V+$ \\
\hline 6 & $50 / F$ & Insulinoma, head-body & $5.5 \times 10.2$ & FNA + & $V+$ \\
\hline 7 & $48 / \mathrm{M}$ & MEN-1/Uncinate-tail & $20 \mathrm{~mm}$ & FNA + & $\begin{array}{l}V+I C C+\text { Gastro-duodenal } \\
<10 \mathrm{~mm} \text { : Biopsias + e ICC Ki } \\
67<5 \% \text { Non-op. }\end{array}$ \\
\hline 8 & 79/M & NF, head (CT: casual) & 12 by 16 & FNA + & $V+I C Q$. No Op. \\
\hline 9 & $41 / F$ & NF, body (NFM on CT) & 12 by 14 & FNA + & $V+I C Q$ \\
\hline 10 & $75 / F$ & Mediastinal (PC) Ki 67 8\% & $66-70 \mathrm{~B}$ & FNA + & $V+I C C$. Non-op. \\
\hline 11 & $68 / F$ & Mediastinal (PC) & $12-16$ & FNA + & $V+\mathrm{IHC} \cdot \mathrm{T} 4 \mathrm{~N} 2$ \\
\hline 12 & $81 / F$ & Rectal carcinoid (41) (42) & $30 \mathrm{~mm} \mathrm{~B}$ & FNA + & $V+I C C$ \\
\hline 13 & $55 / \mathrm{M}$ & Pancreatic gastrinoma, head & $<10 \mathrm{~mm}$ & FNA - & No Op. \\
\hline 14 & $47 / F$ & NF PET US/CT: body & $9 \mathrm{~mm}$ & FNA - & V - . No Op. \\
\hline 15 & $45 / \mathrm{M}$ & MEN-1/Retro/Ca-body 5-10-20-40 & & FNA + & $\begin{array}{l}V+\text { ICC Gastro-duodenal C-A \& } \\
\text { serotonin }+<5 \mathrm{~mm} \text { Non-op. }\end{array}$ \\
\hline 16 & $92 / F$ & NF PET on CT, head & $23-26 \mathrm{~mm}$ & FNA + & $V+$ ICC. Non-op. \\
\hline
\end{tabular}

NF PET: Non-functional pancreatic endocrine tumor. PC: Pulmonary carcinoid. Non-op.: Non-operated

ICC/IHC:

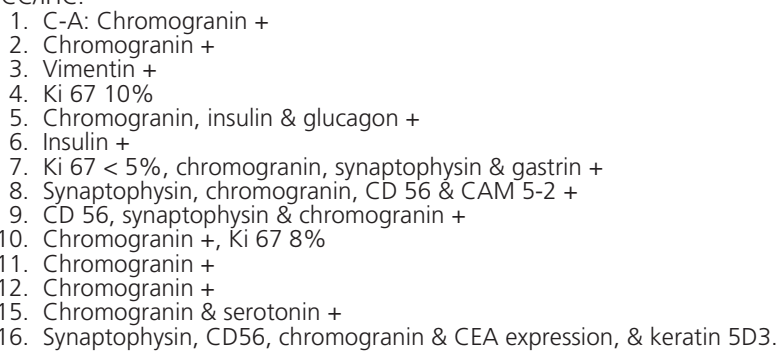

Table II. Literature overview

\begin{tabular}{|c|c|c|}
\hline Ciaccia $1998(6)$ & 19 c. TNES & S: $84 \%$ ? 0\% F + (Sp: 100\%) \\
\hline Voss 2000 & 15 c. in 99 patients (15\%) & P: $46.7 \%$ NET vs. $81 \%$ Adenoca. \\
\hline Gress 2002 & 1 c. Tattooed insulinoma & \\
\hline Jhala 2002 & 9 c. citology \& ICC + & S. $100 \%(2 / 2)$ \\
\hline Ginès 2002 & 10 c. with 14 NETs & $\begin{array}{l}\text { P: \& S: } 90 \% \text { Sp: } 100 \% 7 \text { c. surgical } \\
\text { confirmation }\end{array}$ \\
\hline Santo 2002 & 76 c. (47 F) & P: 94\% S: 96\% \\
\hline Ardengh 2004 & 30 c. with 33 NETs & P y S: 83\% Sp: 85.7\% \\
\hline Gu 2005 & 30 c. IHC $(C-A)+$ in all & $100 \%$ \\
\hline Chang 2006 & 9 c. FNA \& ICC & $89 \%(8 / 9)$ \\
\hline Baker 2007-8 & 13 C./ 9 C with ICC (C-A \& synaptophysin) & $9 / 9100 \%$ \\
\hline Pais 2007 & 76 c. FNA & S: $86 \%$ \\
\hline Jani 2008 & 41 c. in 4 a. FNA: $8 \%$ C, $15 \%$ F \& $85 \%$ NF & \\
\hline Chatzipantelis-08 & 48 c. $(40 / 48$ ICC: $83 \%)$ & $83 \% 7 \%$ inadequate \\
\hline Kongkam 2008 & 9 c. Qysctic (9\%) FNA \& ICC + C \& S: & $100 \%$ \\
\hline Alsohaibani 2008 & 14 c. EUS: $100 \%$ & FNA: $90 \%(9 / 10)$ \\
\hline Charfi 2009 & 6 c. Q with ICC + in all & $100 \%(6 / 6)$ \\
\hline Figueiredo 2009 & 86 c./ 77 c. $(90 \%)$ FNA \& ICC. $9 \%$ C \& 14\% F 100\% (10c.) & \\
\hline Piani 2008 & 18 c. FNA \& Ki $67<2 \%: 89 \%$ & \\
\hline Alesiev 2009 & 15 c. ICQ \& Ki 67 & \\
\hline Chatzipantelis-09 & 35 c. Ki 67: prognosis marker & \\
\hline Fasanella 2009 (28) & 29 c. Microsatellites. FAL $<0.2$ benign & \\
\hline Gornals 2010 & 16 c (9 with surgical confirmation) PPV: $89 \%$ S: $100 \%$ (9c.) & \\
\hline Summary: & $>500 \mathrm{c}$ & P: $81 \%$ S: $94 \%$ Sp: $95 \%$ \\
\hline
\end{tabular}




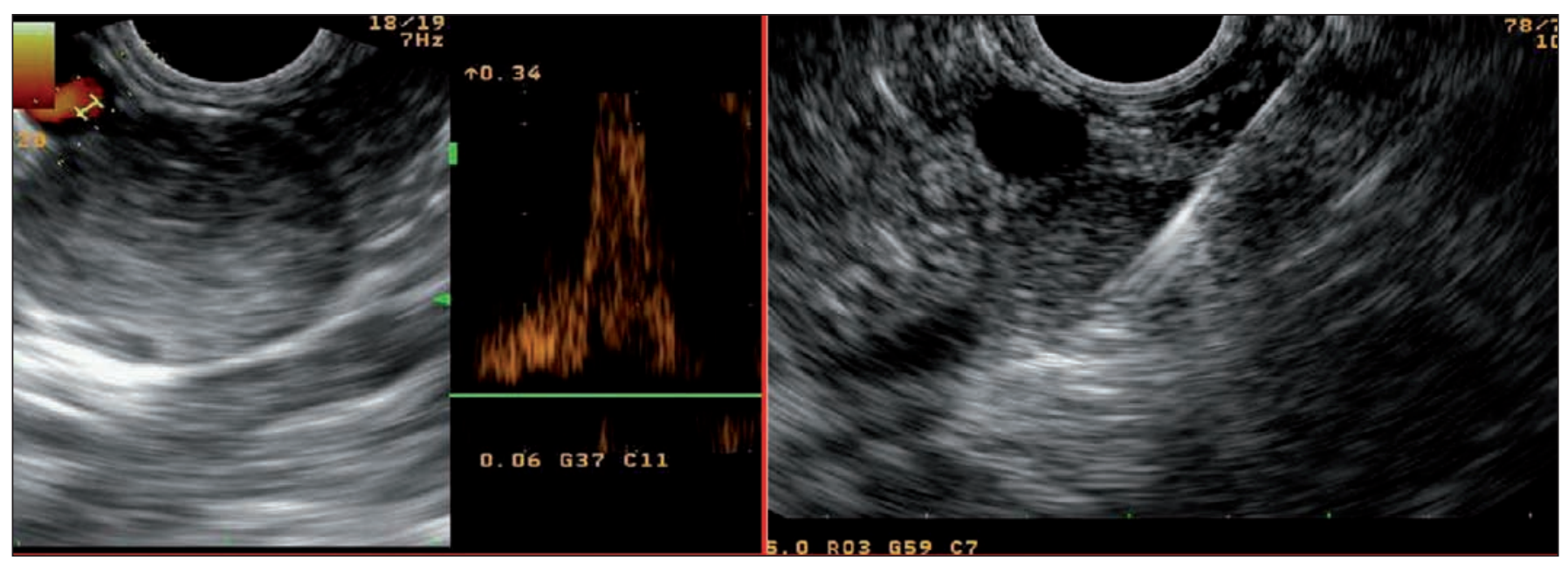

Fig. 1. Pancreatic EUS: PET and EUS-FNA.

FNA-collected samples (30-33): most were vimentin+ and cytokeratin+, whereas chomogranin and NSE were negative (they may be focally positive though) (34).

In this multicenter study in 28 patients with pseudopapillary tumors (34) a preoperative diagnosis was reached for 21 cases (75\%); vimentin, alfa1-antitrypsin, CD10, and beta-catenin were positive in all cases, whereas chromogranin was positive in just $1 / 20(5 \%)$ and synaptophysin in 10/17 (59\%); however, the best marker to tell endocrine tumors from solid pseudopapillary tumors was E-cadherin/B-catenin/CD10 according to a recent study (35).

In our case with a solid pancreatic pseudopapillary tumor IHC was key for a definitive diagnosis. False positive results have been described in other series $(12,18)$.

A recent Japanese study (36) reviewed 455 pancreatic FNA procedures: 28 were rare pancreatic tumors (no duc-

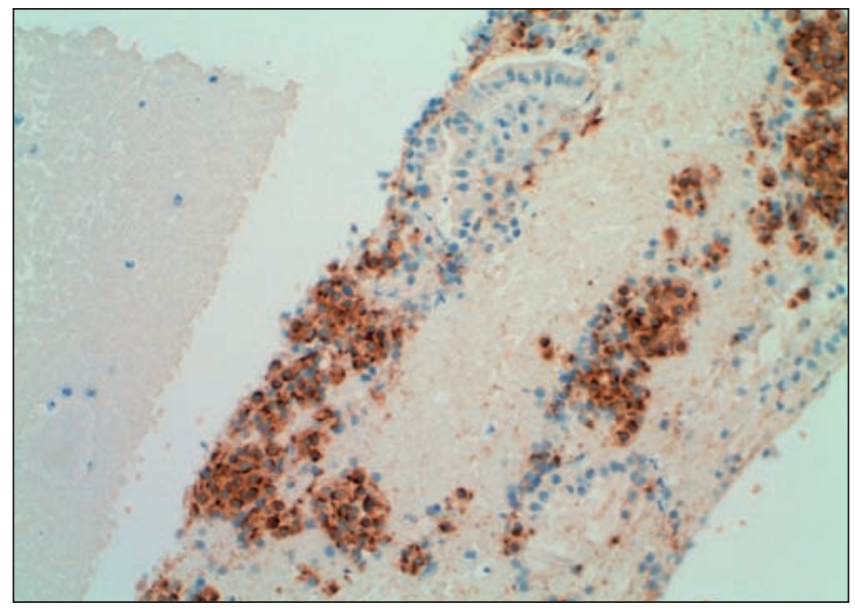

Fig. 2. ICC: chomogranin A+ tal adenocarcinomas). EUS-FNA with cytology, cellblock, and immunocytochemistry correctly diagnosed tumor type in 19 patients 19 (68\%).

In differentiating benign from malignant tumors it had a sensitivity of $69 \%$, a specificity of $100 \%$, a PPV of $100 \%$, a NPV of $79 \%$, and a precision of $86 \%$. None of the three malignant pancreatic endocrine tumors was diagnosed as such. EUS-FNA changed the presumed diagnosis in 11 cases $(39 \%)$.

Four cases have been recently reported (37) where small $(8-16 \mathrm{~mm})$, non-functioning pancreatic endocrine tumors were found together with intraductal papillary mucinous neoplasms. PNETs remained undetected by common imaging techniques (CT and MRI); $3 / 4$ were diagnosed using EUS, and only 1/3 using EUS-FNA.

To conclude, ICC on cytology samples collected by EUS-FNA is key for a definitive diagnosis of PNETs. Our study (S: 100\%) (PPV: 89\%) confirmed the findings in the literature (mean sensitivity of $94 \%$, mean specificity of $95 \%$ ) (Table II).

Notwithstanding, the diagnostic panel is increasingly greater, and novel markers emerge including SERPINB8 (38), which is as sensitive as C-A and synaptophysin, or CDX-2, PDX-1, NESP-55 and TTF-1, which may help in the differential diagnosis between gastrointestinal and pulmonary carcinoids, and pancreatic endocrine tumors (39), with CK 19 being an independent prognostic factor for PNETs, particularly non-insulinomas according to a recent review (40). However, chromogranin and synaptophysin remain the key markers since many years ago (43) to this day (44).

Thus, believe that ICC is key for a definitive diagnosis of NETs (45), a statement not fully shared by other teams (44). 


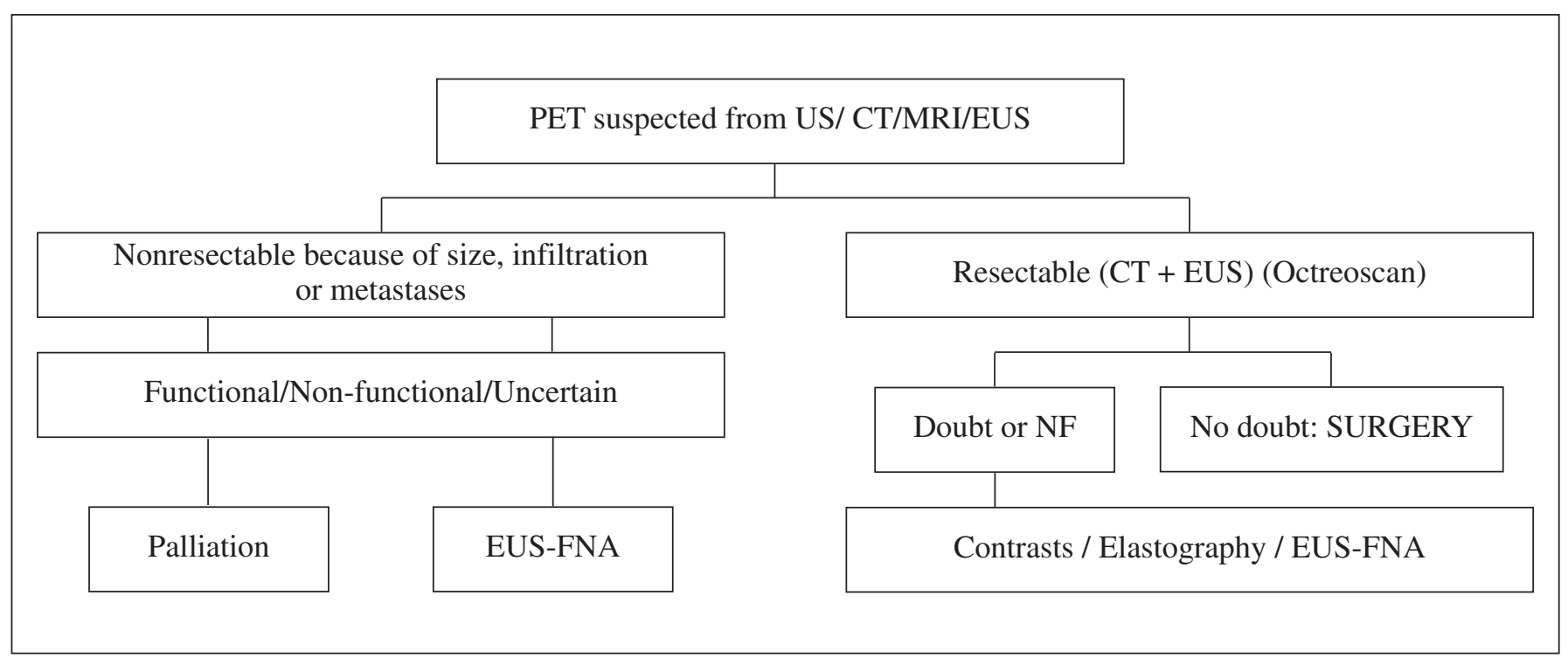

Fig. 3. Algorithm.

\section{REFERENCES}

1. Varas MJ, Miquel JM, Maluenda MD, et al. Preoperative detection of gastrointestinal neuroendocrine tumors using endoscopic ultrasonography. Rev Esp Enferm Dig 2006;98:828-36.

2. Kloppel G. Tumour biology and histopathology of neuroendocrine tumours. Best Pract Res Clin Endocrinol Metab 2007;21:15-31.

3. Metz DC, Jensen RT. Gastrointestinal neuroendocrine tumors: pancreatic endocrine tumors. Gastroenterology 2008;135:1469-92.

4. McLean AM, Fairclough PD. Endoscopic ultrasound in the localization of pancreatic islet cell tumours. Best Pract Res Clin Endocrinol Metab 2005; 19:177-93.

5. Varas MJ. Neuroendocrine tumors -fascination and infrequency. Rev Esp Enferm Dig 2009;101:195-208.

6. Ciaccia D, Harada N, Wiersema MJ, et al. Preoperative localization and diagnosis of pancreatic and pancreatic islet cell tumors using endoscopic ultrasound guided fine needle aspiration: a multicenter experience. Gastrointest Endosc 1997;45:AB170.

7. Voss M, Hammel P, Molas G, et al. Value of endoscopic ultrasound guided fine needle aspiration biopsy in the diagnosis of solid pancreatic masses. Gut 2000;46:244-9.

8. Gress PG, Barawi M, Kim D, et al. Preoperative localization of a neuroendocrine tumors of the pancreas with EUS-guided fine needle tattooing. Gastrointest Endosc 2002;55:594-7.

9. Jhala D, Eloubeidi M, Chhieng DC, et al. Fine needle aspiration biopsy of the islet cell tumor of pancreas: a comparison between computerized axial tomography and endoscopic ultrasound-guided fine needle aspiration biopsy. Ann Diagn Pathol 2002;6:106-12.

10. Ginès A, Vazquez-Sequeiros E, Soria MT, et al. Usefulness of EUS-guided fine needle aspiration (EUS-FNA) in the diagnosis of functioning neuroendocrine tumors. Gastrointest Endosc 2002;56: 291-6.

11. Santo E, Kariv R, Monges G, et al. The role of linear array endoscopic ultrasound with fine-needle aspiration in the diagnosis and preoperative evaluation of pancreatic neuroendocrine tumors -experience with 76 cases. Gastrointest Endosc 2002;56:S118.

12. Ardengh JC, de Paulo GA, Ferrari AP. EUS-guided FNA in the diagnosis of pancreatic neuroendocrine tumors before surgery. Gastrointest Endosc 2004;60:378-84.

13. Gu M, Ghafari S, Lin F, et al. Cytological diagnosis of endocrine tumors of the pancreas by endoscopic ultrasound-guided fine-needle aspiration biopsy. Diagn Cytopathol 2005;32:204-10.

14. Chang F, Vu C, Chandra A, et al. Endoscopic ultrasound-guided fine needle aspiration cytology of pancreatic neuroendocrine tumours: cy- tomorphological and immunocytochemical evaluation. Diagn Cytopathol 2006;17:10-7.

15. Baker MS, Knuth JL, DeWitt J, et al. Pancreatic cystic neuroendocrine tumors: preoperative diagnosis with endoscopic ultrasound and fineneedle immunocytology. J Gastrointestinal Surg 2008;12: 450-6.

16. Pais SA, Mcgreevy K, Leblanc JK, et al. Utility of EUS-FNA in the diagnosis of pancreatic neuroendocrine tumors: correlation with histopathology in 76 patients. Gastrointest Endosc 2007; 65: AB 304.

17. Jani N, Khalid A, Kaushik N, et al. EUS-guided FNA diagnosis of pancreatic endocrine tumors: new trends identified. Gastrointest Endosc 2008;67:44-50.

18. Chatzipantelis P, Salla C, Kostantinou P, et al. Endoscopic ultrasound-guided fine-needle aspiration cytology of pancreatic neuroendocrine tumors: a study of 48 cases. Cancer 2008;114:255-62.

19. Kongham P, Al-Haddad M, Attasaranya S, et al. EUS and clinical characteristics of cystic pancreatic neuroendocrine tumors. Endoscopy 2008;40:602-5.

20. Alsohaibani F, Bigam D, Kneteman N, et al. The impact of preoperative endoscopic ultrasound on the surgical management of pancreatic neuroendocrine tumours. Can J Gastroenterol 2008;22:817-20.

21. Charfi S, Marcy M, Bories E, et al. Cystic pancreatic endocrine tumors: an endoscopic ultrasound-guided fine-needle aspiration biopsy study with histologic correlation. Cancer Cytopathol 2009;117:203-10.

22. Figueiredo F, Giovannini M, Monges G, et al. EUS-FNA predicts 5year survival in pancreatic endocrine tumors. Gastrointest Endosc 2009;70:907-14.

23. La Rosa S, Rigoli E, Uccella S, et al. Prognostic and biological significance of cytokeratin 19 in pancreatic endocrine tumours. Histopathology 2007;50:597-606.

24. Piani C, Franchi GM, Cappelleti Ch, et al. Cytological Ki 67 in pancreatic endocrine tumours: an opportunity for pre-operative grading. Endocrine-related. Cancer 2008;15:175-81.

25. Alesiev BA, Darwin PE, Goloubeva O, et al. Proliferative rate in endoscopic ultrasound fine-needle aspiration on pancreatic endocrine tumors: correlation with clinical behavior. Cancer Cytopathol 2009; 117:40-5.

26. Chatzipantelis P, Konstantinou P, Kaklamanos M, et al. The role of cytomorphology and proliferative activity in predicting biologic behavior of pancreatic neuroendocrine tumors: a study by endoscopic ultrasound-guided fine-needle aspiration cytology. Cancer Cytopathol 2009; 117:211-6.

27. Nodit L, McGrath KM, Zahid M, et al. Endoscopic ultrasound-guided fine needle aspirate microsatellite loss analysis and pancreatic endocrine tumor outcome. Clin Gastroenterol and Hepatol 2006;4: 1474-8. 
28. Fasanella KE, McGrath KM, Sanders M, et al. Pancreatic endocrine tumor EUS-guided FNA DNA microsatellite loss and mortality. Gastrointest Endosc 2009;69:1074-80.

29. Varas MJ. Ultrasonografía endoscópica. Aplicaciones diagnósticas y terapéuticas. Madrid: Ed. Medica Panamericana; 2008.

30. Mergener K, Detweller SE, Traverso LW. Solid pseudopapillary tumor of the pancreas: diagnosis by EUS-guided fine-needle aspiration. Endoscopy 2003;35:1083-4.

31. Master SS, Savides TJ. Diagnosis of solid-pseudopapillary neoplasm of the pancreas by EUS-guided FNA. Gastrointest Endosc 2003; 57: 965-8.

32. Bardales RH, Centeno B, Mallery JS, et al. Endoscopic ultrasound-guided fine-needle aspiration cytology diagnosis of solid-pseuopapillary tumor of the pancreas. A rare neoplasm of elusive origin but characteristic cytomorphologic features. Am J Clin Pathol 2004;121: 654-62.

33. Salla C, Chatzipantelis P, Konstantinou P, et al. Endoscopic ultrasound-guided fine-needle aspiration cytology diagnosis of solid pseudopapillary tumor of the pancreas: a case report and literature review. World J Gastroenterol 2007;13:5158-63.

34. Jani N, Dewitt J, Eloubeidi M, et al. Endoscopic ultrasound-guided fine-needle aspiration for diagnosis of solid pseudopapillary tumors of the pancreas: a multicenter experience. Endoscopy 2008;40:200-3.

35. Burford H, Baloch Z, Liu X, et al. E-cadherin/(beta)-Catenin and CD10: A limited immunohistochemical panel to distinguish pancreatic endocrine neoplasm from solid pseudopapillary neoplasm of the pancreas on endoscopic ultrasound-guided fine-needle aspirates of the pancreas. Am J Clin Pathol 2009;132:831-9.

36. Imaoka $\mathrm{H}$, Yamao $\mathrm{K}$, Bhatia $\mathrm{V}$, et al. Rare pancreatic neoplasms: the utility of endoscopic ultrasound-guided fine-needle aspiration -a large single center study. J Gastroenterol 2009;44:146-53.
37. Gill KRS, Scimeca D, Stauffer J, et al. Pancreatic neuroendocrine tumors among patients with intraductal papillary mucinous neoplasms: real association or just a coincidence? J Pancreas (on line) 2009; 10(5): 515-7.

38. De Koning PJ, Bovenschen N, Broekhuizen R, et al. Serine protease inhibitor 8 is a novel immunohistochemical marker for neuroendocrine tumors of the pancreas. Pancreas 2009;38:461-7.

39. Srivastava A, Hornick JL. Immunohistochemical staining for CDX2, PDX-1, NESP-55, and TTF-1 can help distinguish gastrointestinal carcinoid tumors from pancreatic endocrine and pulmonary carcinoid tumors. Am J Surg Pathol 2009;33:626-32.

40. Jain R, Fischer S, Serra S, et al. The use of Cytokeratin (CK 19) immunohistochemistry in lesions of the pancreas, gastrointestinal tract, and liver. Appl Immunohistochem Mol Morphol 2010;18:9-15.

41. Varas MJ, Muñoz F, Espinós JC, et al. Tumores carcinoides digestivos. Rev Esp Enferm Dig 2010;102:533-7.

42. Varas MJ, Gornals JB, Pons C, et al. Utilidad de la ultrasonografía endoscópica (USE) para seleccionar tumores carcinoides como candidatos a una resección endoscópica. Rev Esp Enferm Dig 2010; 102:577-82.

43. Lam KY, Lo CY. Pancreatic endocrine tumor: a 22-year clinicopathological experience with morphological, immunohistochemical observation and review of the literature. Eur J Surg Oncol 1997;23: 36-42.

44. Pais SA, Al-Haddad M, Mohamadnejad M, et al. EUS for pancreatic neuroendocrine tumors: a single-center, 11-year experience. Gastrointest Endosc 2010;71:1185-93.

45. Hosoda W, Takagi T, Mizuno N, et al. Diagnostic approach to pancreatic tumors with the specimens of endoscopic ultrasound-guided fine needle aspiration. Pathol Int 2010; 60: 358-64. 